\title{
IMAGENS DA ADOLESCÊNCIA FEMININA NA REVISTA CAPRICHO
}

\author{
IMAGES OF FEMALE ADOLESCENCE IN THE CAPRICHO \\ MAGAZINE
}

Wanessa Gonçalves dos Santos Couto ${ }^{1}$ Paulo Rogério Meira Menandro

COUTO, W. G. d. S.; MENANDRO, P. R. M. Imagens da adolescência feminina na Revista Capricho. Rev. Bras. Cresc. Desenv. Hum., São Paulo, 2003.

Resumo: Adolescentes são alvos privilegiados por produtos da indústria cultural. Muitas das informações importantes para a sua formação estão disponíveis nos meios de comunicação de massa. Em muitos países, são publicadas revistas de informação e lazer específicas para o consumo da adolescente feminina. O presente trabalho identificou, organizou e analisou interesses, comportamentos e valores retratados em determinadas seções temáticas da revista Capricho de forma a construir um panorama das imagens com que a adolescência feminina é ali representada e idealizada. Foram analisadas 123 matérias jornalísticas sobre diversos aspectos das relações da adolescente com a sociedade, tendo sido feita uma comparação entre aqueles publicados no período 1993/1995 com os publicados no período 1999/2001. A análise dos dados revelou um "modelo ideal” de adolescente que envolve relações sociais e familiares saudáveis e bem adaptadas. Trata-se da adolescente que consegue conjugar: a) autonomia e liberdade com o respeito aos limites; b) valores e convicções com diálogo; c) autovalorização com respeito às diferenças; d) prazeres e lazeres de várias modalidades com responsabilidade e prevenção da vulgaridade, da violência e das doenças; e) o viver plenamente as demandas de sua idade sem deixar de fazer planos e preparar-se para a vida adulta.

Palavras-chave: adolescência; adolescência feminina; meios de comunicação de massa; valores; identidade.

\section{INTRODUÇÃO}

Há mais de quatro décadas, a indústria cultural vem dando especial e crescente atenção à juventude e à adolescência. Mudanças desencadeadas no pós-guerra, que se refletem em processo de modernização social desencadeado na década de 50, colaboraram com a criação de uma cultura juvenil. Segundo ABRAMO (1994), entre tais mudanças estão: o novo ciclo de desenvolvimento industrial, a diversificação da produ- ção e a criação de novos bens de consumo, o pleno emprego, os benefícios do welfare state e a valorização social do tempo livre, vinculada à redução da jornada de trabalho. Outras mudanças atingiram mais diretamente adolescentes e jovens, como: o aumento do período escolar para outros setores sociais além das classes burguesas (que amplia o contingente social abrangido pela noção de juventude), a extensão da escolaridade obrigatória e o aumento da oferta de empregos para os jovens recém-egressos da escola.

1 Programa de Pós-Graduação em Psicologia Universidade Federal do Espírito Santo - UFES. WANESSA COUTO: Rua Padre Antônio Ribeiro Pinto, $n^{\circ} 38$ - Bloco C, Apt $^{\circ} 309$ Praia do Suá - Vitória - ES - CEP: 29052-290 Telefone: 32357679. Endereço Eletrônico: wanessasantos@terra.com.br PAULO MENANDRO: Rua Constante Sodré, 869 - Apt ${ }^{\circ} 201$ - Praia do Canto - Vitória - ES - CEP: 29055420 Telefone: 0xx27 32257165. Endereço Eletrônico: menandro@escelsa.com.br Toda correspondência deve ser enviada para o endereço de Paulo Menandro. 
O aumento do poder de consumo destes jovens empregados formou um novo segmento de mercado, ocasionando rápida resposta da indústria, que passou a gerar bens específicos para tal público, sobretudo bens de diversão. São produtos que se tornam marcas juvenis de novos padrões de comportamentos que remetem à conquista de mais autonomia e liberdade e à contestação ao mundo adulto diferente do deles. Neste contexto, conflito geracional e rebeldia passaram a serem considerados como aspectos inerentes à condição juvenil (ABRAMO, 1994).

Essa cultura juvenil - voltada para prazer e divertimento, e com forte ligação com o consumo - propagou-se por cinema, rádio, TV e imprensa, proporcionando "experiências culturais simultâneas em diferentes partes do mundo” (MIRA, 2001, p.153) e fez da globalização um pressuposto para esse segmento de mercado. SODRÉ (1992) atribui à noção de adolescência uma ligação direta com interesses de mercado, uma vez que a administração atual do espaço social tem forte influência dos meios de comunicação de massa, que “'descobriram' os adolescentes no início dos anos 60 e 'acolheram' parte de sua rebelião como espetáculo" (p. 83).

Alguns autores localizam na transição entre os séculos XIX e XX o momento em que grupos juvenis passam a adotar comportamentos não usuais, contrários às normas sociais vigentes, problematizando o processo de transmissão das mesmas, fazendo com que a juventude despertasse interesse acadêmico e tivesse maior visibilidade (ABRAMO, 1994).

Alguns autores, como discutido por GROPPO (2000), sugerem o uso sociológico no plural do termo juventude, o que melhor se ajustaria à diversidade de realidades em que pode ser vivida tal fase de transição à maturidade. Seria possível dizer, então, que a juventude, como categoria social é

uma representação e uma situação social simbolizada e vivida com muita diversidade na realidade cotidia- na, devido à sua combinação com outras situações sociais - como a de classe ou estrato social - , e também às diferenças culturais, nacionais $e$ de localidade, bem como às distinções de etnia e de gênero (GROPPO, 2000, p. 15).

Mesmo partindo da premissa de que a noção de juventude é socialmente variável, é possível identificar características comuns aos grupos de adolescentes ou jovens de sociedades distintas. ABRAMO (1994) apontou três aspectos básicos que caracterizam a condição de jovem na maior parte das sociedades (inclusive ajudando a entender porque muitas vezes ela pode se manifestar como condição potencialmente problemática).

$\mathrm{O}$ aspecto da transitoriedade é um deles, já que o período em discussão representa, na maioria das vezes, a passagem de uma condição social mais dependente a uma outra mais ampla, a vida social adulta; uma passagem que se subdivide em muitas outras. Tendo em vista a indefinição dos limites de início e término dessa passagem, como também de direitos e deveres da condição juvenil, ela é também caracterizada por ambigüidade. Mesmo quando a juventude se torna mais extensa e percebida como portadora de identidade e cultura próprias, ela ainda é vista também como um período de passagem, transitório e ambíguo, em relação à condição de cidadania plena do adulto, o que constitui uma condição de suspensão da vida social.

Vale registrar que esses aspectos estão potencialmente presentes na adolescência, mas não são exclusivos dela, podendo se manifestar

em alguns estilos de vida adulta. Pode estar em jogo a maior probabilidade de repercussão de tais aspectos na adolescência.

GROPPO (2000) sugeriu, examinando a produção da psicologia sobre adolescência (ou juventude), que a concepção primordial é a de um estágio da vida no qual é definida uma identidade particular. 
STEINBERG e MORRIS (2001) destacaram algumas conclusões gerais sobre comportamento problemático na adolescência que emergiram e que têm moldado a pesquisa sobre o tópico. Referem-se ao reconhecimento da necessidade de: a) distinguir entre experimentação ocasional e padrões duradouros de comportamentos perigosos ou potencialmente causadores de problemas; b) distinguir entre problemas que têm suas origens e início durante a adolescência e aqueles que têm raízes em períodos anteriores; c) reconhecer que muitos dos problemas vividos por adolescentes têm natureza transitória e são resolvidos pelo início da vida adulta, com poucas repercussões de longo prazo.

Esses mesmos autores (STEINBERG \& MORRIS, 2001), na revisão que compreende investigações sobre adolescência feitas durante treze anos, destacaram a tendência de estudo do desenvolvimento adolescente em contexto, isto é, tomando como foco principal não o desenvolvimento e o funcionamento individual, mas sim os contextos nos quais esse desenvolvimento se dá, incluindo família, grupo de pares, escola, situações de trabalho, e toda a diversidade de informações sobre esses contextos que circulam na sociedade. Nosso trabalho se pretende incluso em tal tendência.

Enfocar a adolescente feminina responde a interesse especial de pesquisa. GROPPO (2000) ressaltou a existência de vivências diferenciados da juventude por adolescentes homens e mulheres, "mesmo quando se trata de indivíduos de uma mesma classe ou estrato social, do mesmo ambiente urbano ou rural, etnia, etc.” (p. 6). E possível falar em mais acesso dos homens a um maior leque de atividades, em maior controle físico e psicológico e maior volume de interdições sobre a mulher, em vigência de uma dupla moral sexual, entre outras diferenças. Isso torna o papel da imprensa feminina dirigida às adolescentes proeminente já que pode fornecer informações que estão interditadas por outras vias e ampliar horizontes sobre a vida adulta feminina explorando novas possibilidades sociais; embora também possa contribuir para reforçar estereótipos e posturas conservadoras.

Jornais e revistas têm sido utilizados em ciências humanas como fonte de material para estudos e pesquisas, por proporcionarem caracterizar, ão tão detalhada quanto possível de ocorrências sobre as quais pouca informação existe além daquela contida no registro jornalístico. Além disso, a imprensa escrita tem importancia histórica, por anteceder o rádio e a televisão, e prática, por ser muito diversificada e permitir acesso facilitado devido ao baixo custo de arquivamento e recuperação.

A imprensa feminina teve e tem expressiva participação na construção social do que se entende como ' natureza” feminina no âmbito da cultura brasileira e do que se espera em relação aos comportamentos femininos em várias esferas da vida social, pelo menos para a mulher de nível sécio económico médio ou superior, que é a mais visada pelos veículos femininos, assim como a mulher jovem, "servindo para estimular o mercado ao exigir eterna renovação" (BUITONI, 1986, p. 78). A pesquisa brasileira produziu diversas análises das características e do impacto da imprensa feminina em diferentes momentos da história do país (BUITONI, 1981 1986, BASSANEZI, 1996; PARK, 1999 MARTINS, 2001).

MINAYO et al. (1999) e MIRANDA-RIBEIRO e MOORE (1997) constataram que meios de comunicação como a televisão e as revistas estão entre as principais fontes de informação para os jovens, destacando-se o seu caráter impessoal como favorecedor desta preferência.

No caso das adolescentes a revista tem ainda mais relevância, pois além de trazer informações para consumo individual sobre relacionamentos e sexualidade, apresenta prescrições de comportamentos conectadas com a atualidade já que deve responder às dúvidas e necessidades reais da adolescente daquela geração. Tais revistas contribuem não só para legitimar, mas também para transformar e recriar padrões de comportamentos, interesses e va- 
lores relativos à adolescência e, especialmente, à adolescência feminina.

Nosso estudo pretendeu identificar, organizar e analisar interesses, comportamentos e valores retratados em matérias jornalísticas publicadas em determinadas seções temáticas da revista Capricho, de forma a construir um panorama das imagens com que a adolescência feminina é ali representada e idealizada. Pressupõe-se que essas imagens da adolescência guardem correspondência com as experiências da vida da adolescente brasileira de família com renda média e, portanto, com as questões, preferências e dificuldades dessa adolescência feminina real e atual.

\section{MÉTODO}

\section{A FONTE DE DADOS}

A fonte de dados utilizada foi a revista Capricho, há algumas décadas destinada especificamente ao público adolescente, mas que, quando de seu lançamento (Junho de 1952; Editora Abril), era também destinada às mulheres adultas. Nesta época, com conteúdo de fotonovelas, basicamente, ganhou a preferência das leitoras, tornando-se a revista feminina mais importante e com volume de vendas jamais igualado por qualquer publicação feminina brasileira (BUITONI, 1986, p. 48).

Capricho é a mais conhecida revista brasileira para adolescentes (MIRA,2001). Sua fórmula editorial em vigor a partir de 1982 enfatiza moda, beleza e comportamento adolescente, incluindo sexo, drogas, e relacionamentos interpessoais e intergrupais.

Pelo fato de muitos dos temas abordados, dos exemplos citados, e das soluções sugeridas nas matérias deixarem evidente que a interlocução pressupõe uma leitora de razoável poder aquisitivo, assumimos que a revista está mais direcionada para adolescentes de classes média e alta (embora a revista não assuma tal interpretação). Isso não impede de conside- rarmos que Capricho tem importância destacada já que tais adolescentes compõem um modelo ideal aspirado pela maioria das adolescentes, inclusive as de classes populares (ver ABRAMO, 1994). Trata-se de modelo que pode ser muito influente como gerador de comportamentos e interesses potencialmente adoráveis, pois também está presente em outros canais de informação.

Para ser vendável e atrair mercado de leitoras e de anunciantes, a revista tem que estar inteirada das necessidades, interesses e comportamento da adolescente atual. Para isso Capricho, hoje, conta não só com as cartas das leitoras, mas também com a comunicação e as pesquisas através de seu site.

\section{PROCEDIMENTOS ADO TADOS NA COLETA DOS DADOS}

Estabelecemos dois blocos cronológicos com os quais trabalhamos: 1993 a 1995 (que chamamos de Primeiro Periodo); e 1999 a 2001 (que chamamos de Segundo Periodo). Definimos como alvo de análise uma revista por trimestre em cada um desses seis anos, totalizando 24 edições da revista Capricho.

Os conteúdos veiculados por Capricho podem ser classificados, quanto à temática predominante em oito conjuntos: 1 ) moda ou beleza, novos produtos em geral, sempre com informação mesclada à publicidade; 2) matérias biográficas, cada vez mais com artistas; 3) material publicitário; 4) cartas de leitores com opiniões sobre diversos assuntos veiculados em edições anteriores; 5) testes de conhecimento ou de maturidade sobre diversos assuntos em um âmbito que, de forma geral, poderia ser designado como circunscrito ao universo da vulgarização dos processos psicológicos; 6) processos sociais ou políticos em destaque a partir de algum evento recente, e que têm interesse geral; 7) facetas da diversidade cultural, com abordagem que enfatiza a relação dos jovens com as diferentes situações 
retratadas; 8) aspectos do cotidiano relativos a relacionamento afetivo, amizades, relacionamento familiar, vida escolar, sexualidade, saúde e prevenção de doenças, preconceitos, diferenças entre generos, profissionalização.

Utilizamos o recurso metodológico da Análise de Conteúdo, como proposto por BARDIN (1977). A técnica tem importante função heu^Ii socas ao enriquecer as estratégias exploratorias, aumentando a propensão à descoberta. Seguimos os Ires polos cronologicos propostos: 1) pré-análise; 2) exploração do material; e 3) tratamento dos resultados, inferencia e interpretação (p. 95).

A pré-análise indicou que a investigação poderia ser conduzida de forma pertinente e com muitos subsídios a partir das maténlias reunidas nos blocos 6, 7 e 8, mencionados acima. Essas matérias constituíam os relatos com mais menções aos interesses das adolescentes, às suas preocupações, às prescrições de com- portamentos, às enfâses em determinados valores, às características pessoais ou comportamentais valorizadas ou desvalorizadas, as implicações das ações de cada um em termos de seu universo pessoal, familiar e social.

Tais matérias constituíam uma mesma seção da revista. De 1993 a 1995, tal seção intitulava-se Comportamento. Em 1999, passou a c amar-se Sua Vida. Nos anos 2000 e 2001 a mesma seção ganhou o nome Vida Real.

Para selecionar uma edição em cada trimestre, utilizamos um triplo critério: aquela com matérias mais ricas em discussões e prescrições de comportamentos, que ao mesmo tempo incluísse matérias mais típicas do acervo geral da revista, e que apresentasse ainda uma boa diversidade de matérias na seção sob exame.

Para organizar as informações colhidas nas matérias, foi confeccionada uma ficha de coleta de informações, composta dos seguintes itens:

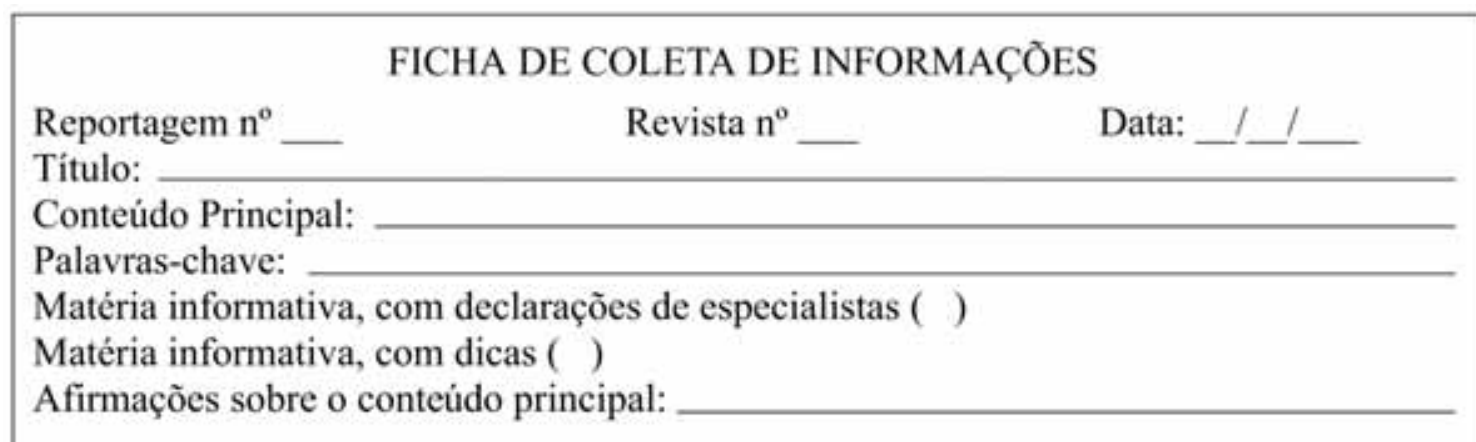

Como agir (dentro do tema):

Temas negativamente valorizados:

Temas positivamente valorizados:

Grupos de valores enfatizados: 
Para a classificação das matérias utilizamos um conjunto de categorias construído a partir da exploração do material e das afinidades das palavras-chave descritoras de tais matérias. Tais categorias, que chamamos de Grandes Temas, são: I) Conquista, ficar, namoro, relações sexuais; II) Conquista, ficar, namoro, relações sexuais (ótica masculina); III) Individualidade, normalidade, autovalorização, habilidade social; IV) Relações familiares; V) Profissões; VI) Diferenças de gênero, comportamento masculino (geral); VII) Drogas; VIII) Turma; IX) Religião, crenças; X) Política; XI) Estudo, escola; XII) Violência sexual; XIII) Relacionamentos pessoais mediados pela Internet; XIV) Viagens, aventuras; XV) Ídolo; XVI) Outros.

Em muitas matérias é possível perceber ênfase em determinadas formas de comportamento, tomadas como mais razoáveis, ou mais prudentes, ou mais aceitáveis, por corresponderem aos modelos preferidos ou recomendados por segmentos sociais que se encontram no âmbito de influência e de consumo da revista. Isso nos levou à estratégia de verificar, em cada matéria jornalística analisada, que valores estavam sendo representados e privilegiados, quando fosse o caso.

TAMAYO (1997) afirmou que:

Do ponto de vista da compreensão psicológica, o sentido com o qual são usadas as palavras na linguagem quotidiana é mais importante do que o sentido técnico das mesmas. A palavra valor diz respeito à oposição que o ser humano estabelece entre o principal e o secundário, entre o essencial e o acidental, entre o desejável e o indesejável, entre o significante e o insignificante. Ela expressa a ausência de igualdade entre as coisas, os fatos, os fenômenos ou as idéias. Desta forma, a palavra valor aplica-se em todas aquelas circunstâncias em que uma delas é julgada superior à outra, em que uma delas é objeto de uma preferência. O valor implica, portanto, o rompimento da indiferença do sujeito diante dos objetos, dos eventos ou das idéias. A manifestação de preferência por algo ou por alguém é, talvez, o comportamento mais comum da vida cotidiana. Neste sentido, a palavra valor expressa uma experiência comum a todo ser humano (TAMAYO, 1997:116).

Verificar que tipos de valores são privilegiados por um veículo de imprensa dirigido a adolescentes é especialmente importante por este ser um grupo em formação, do ponto de vista social, no qual a adesão a valores ainda está parcialmente em processo.

Para considerar as menções a valores diluídas nos textos utilizamos como ferramenta, na organização e na análise de nossos dados, o modelo de representação de valores desenvolvido por TAMAYO e SCHWARTZ (1993). Não nos ocupamos com a discussão teórica em torno de valores, mas apenas utilizamos as categorias (Grupos de Valores) de um modelo já disponível como recurso metodológico complementar.

Apresentamos a seguir o Quadro 1 que mostra os dez Grupos de Valores, sua associação com os fatores de ordem superior, os tipos de interesses a que servem, e um conjunto de exemplos de fenômenos e situações abrangidos em cada caso.

\section{RESULTADOS E DISCUSSÃO}

\section{INFORMAÇÕES INICIAIS}

Foram analisadas 123 matérias publicadas em CAPRICHO. As Tabelas 1 e 2 resumem as freqüências de matérias que mencionam cada um dos Grupos de Valores, por Categorias de Grandes Temas (para o Primeiro e o Segundo Período, respectivamente). 
Quadro 1. Demonstrativo dos Grupos de Valores, com os respectivos Fatores de Ordem Superior e Interesses a que servem.

\begin{tabular}{|c|c|c|c|}
\hline $\begin{array}{l}\text { Grupos de } \\
\text { Valores }\end{array}$ & \begin{tabular}{|c|} 
Fatores de Ordem \\
Superior
\end{tabular} & $\begin{array}{c}\text { Interesses aos quais } \\
\text { Servem }\end{array}$ & Exemplos \\
\hline 1 Hedonismo & $\begin{array}{l}\text { Autopromoção } \\
\text { Abertura }\end{array}$ & $\begin{array}{l}\text { INDIVIDUAIS } \\
\text { (prazer e gratificação } \\
\text { sensual para si mesmo) }\end{array}$ & $\begin{array}{l}\text { Desfrutar da vida; gozar a vida; } \\
\text { satisfazer todos os desejos; obter } \\
\text { prazer sexual, apreciar artes, música, } \\
\text { literatura; ver coisas belas. }\end{array}$ \\
\hline 2 Realização & Autopromoção & $\begin{array}{l}\text { INDIVIDUAIS } \\
\text { (sucesso pessoal obtido } \\
\text { através de demonstração } \\
\text { de competência) }\end{array}$ & $\begin{array}{l}\text { Éxito; obter o que se propõe; ser } \\
\text { eficiente em tudo que faz; ter } \\
\text { ambição; obter sucesso. }\end{array}$ \\
\hline 3 Poder Social & Autopromoção & $\begin{array}{l}\text { INDIVIDUAIS } \\
\text { (controle sobre pessoas e } \\
\text { recursos, prestigio) }\end{array}$ & $\begin{array}{l}\text { Poder; influenciar os outros e } \\
\text { controlar decisões; ser chefe; ter } \\
\text { prestigio; ser conhecido e admirado; } \\
\text { autoridade; vaidade; riqueza. }\end{array}$ \\
\hline $4 \begin{array}{c}\text { Auto- } \\
\text { determinação }\end{array}$ & Abertura & $\begin{array}{l}\text { INDIVIDUAIS } \\
\text { (independência de } \\
\text { pensamento, ação e opção) }\end{array}$ & $\begin{array}{l}\text { Autodireção; estar livre para se } \\
\text { mover; ir e vir sem impedimentos; ser } \\
\text { livre para vestir-se como queira; ter } \\
\text { vida privada sem interferência de } \\
\text { outros; independência; criatividade; } \\
\text { conhecer coisas novas. }\end{array}$ \\
\hline 5 Estimulação & Abertura & $\begin{array}{l}\text { INDIVIDUAIS } \\
\text { (excitação, novidade, } \\
\text { mudança, desafio) }\end{array}$ & $\begin{array}{l}\text { Buscar aventuras; desafiar o perigo; } \\
\text { participar de todas as atividades, se } \\
\text { for possivel; fazer coisas que } \\
\text { permitam estar ocupado, em } \\
\text { movimento; vida excitante; fuga da } \\
\text { monotonia. }\end{array}$ \\
\hline 6 Conformidade & Conservação & $\begin{array}{l}\text { COLETIVOS } \\
\text { (controle de impulsos e } \\
\text { ações que podem violar } \\
\text { normas sociais ou } \\
\text { prejudicar aos outros) }\end{array}$ & $\begin{array}{l}\text { Obediência; cumprir deveres e } \\
\text { obrigaçoes; respeitar aos pais e aos } \\
\text { mais velhos; autodisciplina; controle } \\
\text { de impulsos que possam violar } \\
\text { normas e prejudicar aos outros. }\end{array}$ \\
\hline 7 Tradição & Conservação & $\begin{array}{l}\text { COLETIVOS } \\
\text { (respeito e aceitação dos } \\
\text { ideais e costumes da } \\
\text { sociedade) }\end{array}$ & $\begin{array}{l}\text { Seguir normas sociais e culturais do } \\
\text { pais; respeitar as tradições da } \\
\text { sociedade; segurança familiar; } \\
\text { religiosidade; acreditar no poder de } \\
\text { divindades e aceitar suas orientações. }\end{array}$ \\
\hline 8 Benevolência & Auto-transcendência & $\begin{array}{l}\text { COLETIVOS } \\
\text { (promoção do bem estar } \\
\text { das pessoas intimas) }\end{array}$ & $\begin{array}{l}\text { Honestidade; honradez; amizade; } \\
\text { lealdade; convivência pacifica; ter } \\
\text { relação de afeto profunda e } \\
\text { duradoura; compartilhar a vida; amor; } \\
\text { promoção do bem estar das pessoas } \\
\text { com quem se relaciona. }\end{array}$ \\
\hline 9 Segurança & Conservação & $\begin{array}{l}\text { MISTOS } \\
\text { (integridade pessoal, } \\
\text { estabilidade da sociedade, } \\
\text { do relacionamento e de si } \\
\text { mesmo) }\end{array}$ & $\begin{array}{l}\text { Ordem social; estabilidade social; } \\
\text { estabilidade pessoal; ter vida } \\
\text { organizada; integridade pessoal; } \\
\text { sobrevivência; preocupar-se com a } \\
\text { saúde; ter certeza do amanhã. }\end{array}$ \\
\hline 10 Universalismo & Auto-transcendência & $\begin{array}{l}\text { MISTOS } \\
\text { (tolerância, compreensão e } \\
\text { promoção do bem-estar de } \\
\text { todos e da natureza) }\end{array}$ & $\begin{array}{l}\text { Justiça social; lutar pelo fim das } \\
\text { diferenças; tolerância; promoção do } \\
\text { bem estar geral; preocupação com o } \\
\text { ambiente; cooperação. }\end{array}$ \\
\hline
\end{tabular}


Tabela 1. Freqüências das matérias que mencionam cada um dos Grupos de Valores, por Categorias de Grandes Temas - Primeiro Período: 1993 a 1995.

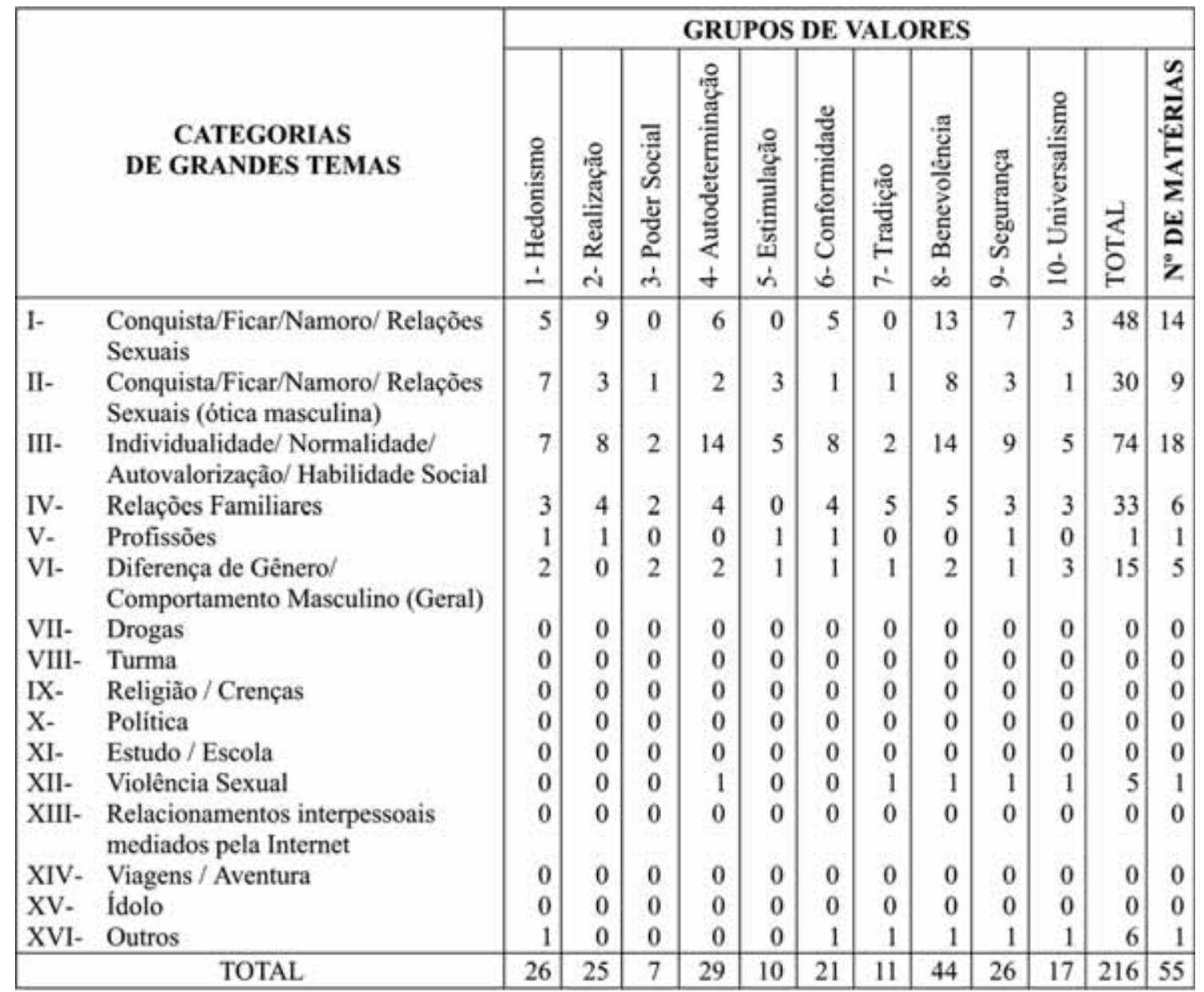

É possível dizer, inicialmente, que, no Primeiro Período $\left(1^{\circ} \mathrm{P}\right)$, representado por 55 matérias, houve 216 menções a Grupos de Valores (média de 3,9 Grupos por matéria). No Segundo Período $\left(2^{\circ} \mathrm{P}\right)$, representado por 68 matérias, houve 264 menções a Grupos de Valores (3,9 Grupos por matéria), evidenciando surpreendente equivalência.

Com relação às categorias de Grandes Temas, destacou-se a fato de que a diversidade temática no $2^{\circ} \mathrm{P}$ aumentou grandemente em relação ao $1^{\circ} \mathrm{P}\left(8\right.$ Categorias no $1^{\circ}$ e 15 no $\left.2^{\circ}\right)$. Em relação à questão da maior variedade temática percebida no $2^{\circ} \mathrm{P}$, é possível que faça parte de uma tendência atual que vem aumentando os temas de relevância social em diversos tipos de periódicos ou suplementos juvenis conforme identificado pela Pesquisa Os Jovens na Mídia (ANDI / IAS / UNESCO, 1999).

Enquanto a maioria das menções a Grupos de Valores no $1^{\circ} \mathrm{P}$ se deu nas quatro primeiras Categorias de Grandes Temas (85,7\%); no $2^{\circ} \mathrm{P}$, apenas $31,4 \%$ das menções ocorreram nessas Categorias, ou seja, os $68,6 \%$ restantes das menções a Grupos de Valores distribuíramse nas outras 11 Categorias.

Destacou-se ainda uma Categoria com acentuada relevância no $1^{\circ} \mathrm{P}$, a Categoria III de 
Tabela 2. Freqüências das matérias que mencionam cada um dos Grupos de Valores, por Categorias de Grandes Temas - Segundo Período: 1999 a 2001.

\begin{tabular}{|c|c|c|c|c|c|c|c|c|c|c|c|c|c|}
\hline & \multirow[b]{2}{*}{$\begin{array}{c}\text { CATEGORIAS } \\
\text { DE GRANDES TEMAS }\end{array}$} & \multicolumn{12}{|c|}{ GRUPOS DE VALORES } \\
\hline & & 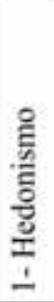 & 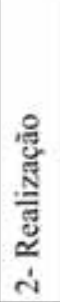 & 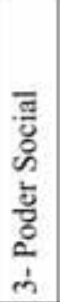 & 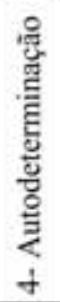 & 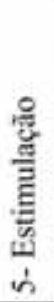 & 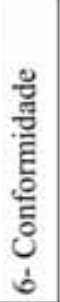 & 冚 & 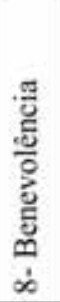 & 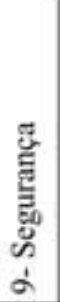 & 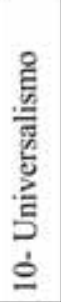 & $\frac{3}{6}$ & 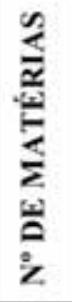 \\
\hline I- & $\begin{array}{l}\text { Conquista/Ficar/Namoro/ Relações } \\
\text { Sexuais }\end{array}$ & 7 & 3 & 0 & 7 & 2 & 3 & 1 & 10 & 8 & 2 & 43 & 15 \\
\hline II- & $\begin{array}{l}\text { Conquista/Ficar/Namoro/ Relações } \\
\text { Sexuais (ótica masculina) }\end{array}$ & 3 & 2 & 1 & 2 & 0 & 2 & 4 & 3 & 1 & 2 & 20 & $7 / 5^{*}$ \\
\hline III- & $\begin{array}{l}\text { Individualidade/ Normalidade/ } \\
\text { Autovalorização/ Habilidade Social }\end{array}$ & 1 & 0 & 1 & 0 & 0 & 1 & 0 & 0 & 0 & 0 & 3 & 1 \\
\hline IV- & Relações Familiares & 1 & 1 & 0 & 2 & 1 & 2 & 3 & 3 & 2 & 2 & 17 & 3 \\
\hline V- & Profissões & 3 & 6 & 4 & 2 & 1 & 3 & 1 & 3 & 0 & 1 & 24 & 6 \\
\hline VI- & $\begin{array}{l}\text { Diferença de Gênero/ } \\
\text { Comportamento Masculino (Geral) }\end{array}$ & 0 & 0 & 0 & 0 & 0 & 0 & 0 & 0 & 0 & 0 & 0 & 0 \\
\hline VII- & Drogas & 1 & 2 & 0 & 2 & 0 & 1 & 1 & 2 & 5 & 1 & 15 & 5 \\
\hline VIII- & Turma & 0 & 2 & 1 & 3 & 2 & 3 & 0 & 3 & 3 & 2 & 19 & 4 \\
\hline IX- & Religião / Crenças & 0 & 2 & 0 & 1 & 0 & 1 & 3 & 2 & 1 & 1 & 11 & 4 \\
\hline$X-$ & Política & 0 & 1 & 0 & 2 & 1 & 1 & 1 & 2 & 1 & 4 & 13 & 5 \\
\hline XI- & Estudo / Escola & 1 & 3 & 1 & 2 & 1 & 2 & 0 & 2 & 1 & 0 & 13 & 3 \\
\hline XII- & Violência Sexual & 1 & 1 & 0 & 2 & 0 & 2 & 1 & 2 & 2 & 1 & 12 & 2 \\
\hline XIII- & $\begin{array}{l}\text { Relacionamentos interpessoais } \\
\text { mediados pela Internet }\end{array}$ & 2 & 1 & 1 & 4 & 2 & 1 & 0 & 2 & 1 & 0 & 14 & 4 \\
\hline XIV- & Viagens / Aventura & 3 & 3 & 0 & 3 & 3 & 1 & 1 & 3 & 2 & 0 & 19 & 3 \\
\hline XV- & Ídolo & 2 & 1 & 1 & 2 & 1 & 0 & 0 & 2 & 1 & 1 & 11 & 2 \\
\hline XVI- & Outros & 3 & 2 & 4 & 2 & 2 & 4 & 4 & 2 & 3 & 4 & 30 & 6 \\
\hline & TOTAL & 28 & 30 & 14 & 36 & 16 & 27 & 20 & 41 & 31 & 21 & 264 & 68 \\
\hline
\end{tabular}

* Nesta Categoria foram consideradas 5 matérias, mais partes de 2 matérias da Categoria I.

** Na categoria XVI - Outros, as 6 matérias encontradas são sobre os temas: Festas, Violência, Preconceito, Distúrbios Alimentares, Meio Ambiente e Culturas.

Grandes Temas - Individualidade / Normalidade / Autovalorização / Habilidade Social (18 matérias no $1^{\circ} \mathrm{P}$ e 1 no $2^{\circ} \mathrm{P}$ ), na qual houve grande concentração das menções a Grupos de Valores (74 menções ou 34,3\% de todas as menções do $\left.1^{\circ} \mathrm{P}\right)$.

São matérias que apontam a necessidade da adolescente refletir sobre si mesma, sobre autovalorização, sobre preservação das suas especificidades, sobre manutenção das suas vontades frente às vontades alheias, mas, ao mesmo tempo, enfatizam comportamen- tos de conformidade e tolerância em várias situações.

Uma característica peculiar nos textos do $2^{\circ} \mathrm{P}$, foi a ênfase em prescrições a partir de consulta a especialistas (foram consultados 22 especialistas no $1^{\circ} \mathrm{P}$ e 47 no $2^{\circ}$ ). Não é improvável que essa participação mais efetiva de especialistas tenha contribuído para a redução de textos argumentativos, que forçam a reflexão, gerando textos com respostas às questões mais diretas e baseadas em conhecimentos legitimados "cientificamente". 


\section{GRUPOS DE VALORES MAIS CITADOS}

O Grupo de Valores mais citado em ambos os períodos foi o Grupo denominado Benevolência. Verificamos que foi um Grupo de Valores bastante enfatizado no $1^{\circ} \mathrm{P}$ no contexto das relações da adolescente com as pessoas próximas: familiares, amigos, vizinhos, namorados e "ficantes". Já no $2^{\circ} \mathrm{P}$, as menções à Benevolência recaem em assuntos relacionados ao namoro e ao "ficar". Autodeterminação foi o segundo Grupo de Valores mais mencionado, em ambos os períodos.

Apesar de algumas diferenças de menções a certos Grupos de Valores dentro de Categorias de Grandes Temas, como veremos a seguir, foi observada grande semelhança nas menções aos Grupos de Valores, entre os dois Períodos, quando considerados os "fatores de ordem superior" associados (Autopromoção, Abertura, Conservação e Autotranscendência) e os "interesses a que servem" (Individuais, Coletivos ou Mistos), como pode ser visto nas

\section{Tabelas 3 e 4.}

Fica evidente a estabilidade nas características dos Grupos de Valores mencionados nas matérias de Capricho, nos dois períodos analisados.

\section{MENÇÕES AOS GRUPOS DE VALORES POR CATEGORIAS DE GRANDES TEMAS}

A) CONQUISTA-FICAR-NAMORO-RELAÇÕES SEXUAIS - Categoria com a maior quantidade de matérias (29) e de menções a grupos de valores (91) considerando-se os dois períodos analisados. O número de matérias e o percentual de menções a valores foi equilibrado nos dois períodos. A diferença mais expressiva entre os dois períodos, foi a de diminuição, no $2^{\circ} \mathrm{P}$, das menções ao Grupo de Valores Realização.

B) CONQUISTA-FICAR-NAMORO-RELAÇÕES SEXUAIS (Ótica Masculina) - Ca-
Tabela 3. Freqüências e Percentuais de Menções aos Fatores de Ordem Superior Associados aos Grupos de Valores - Primeiro Período: 1993 a 1995; e Segundo Período: 1999 a 2001.

\begin{tabular}{|c|c|c|c|}
\hline $\begin{array}{r}\text { Fato } \\
\text { Ordem }\end{array}$ & $\begin{array}{l}1993 / \\
1995\end{array}$ & $\begin{array}{l}1999 / \\
2001\end{array}$ & Total \\
\hline Asso & freq. $\%$ & freq. $\%$ & freq. $\%$ \\
\hline utopron & $58 \quad 24,0$ & $72 \quad 24,7$ & $130 \quad 24,3$ \\
\hline$a b$ & $\begin{array}{ll}65 & 26,8\end{array}$ & $\begin{array}{ll}79 & 27,1\end{array}$ & 14427,0 \\
\hline Cons & $58 \quad 24,0$ & $\begin{array}{ll}79 & 27,1\end{array}$ & 13725,7 \\
\hline Autotransc & $61 \quad 25,2$ & 6120,9 & 12222,9 \\
\hline Total & 242 & 292 & 534 \\
\hline
\end{tabular}

Tabela 4. Freqüências e Percentuais de Menções aos Interesses a que servem os Grupos de Valores - Primeiro Período: 1993 a 1995; e Segundo Período: 1999 a 2001

\begin{tabular}{|c|c|c|c|c|c|}
\hline \multirow{2}{*}{$\begin{array}{c}\text { Fatores de } \\
\text { Ordem Superior } \\
\text { Associados }\end{array}$} & \multicolumn{2}{|c|}{$\begin{array}{l}1993 / \\
1995\end{array}$} & \multicolumn{2}{|c|}{$\begin{array}{c}1999 / \\
2001\end{array}$} & Total \\
\hline & freq & $\%$ & freq. & $\%$ & freq. $\%$ \\
\hline Individu & 97 & 44,9 & 124 & 47,0 & 22146,0 \\
\hline & 76 & 35,2 & 88 & 33,3 & 16434,2 \\
\hline & 43 & 19,9 & 52 & 19,7 & $\begin{array}{ll}95 & 19,8\end{array}$ \\
\hline Total & 216 & & 264 & & 480 \\
\hline
\end{tabular}

tegoria com uma interessante diferença quanto aos grupos de valores citados. No $1^{\circ}$ P, houve predominância marcante de menções aos Grupos de Valores Benevolência e Hedonismo. Já no $2^{\circ} \mathrm{P}$, observou- se o surgimento de outro destaque: Tradição, seguido de Benevolência e Hedonismo.

As menções ao Grupo de Valores Tradição explicam-se pela acentuada desvalorização de atitudes femininas que revelam excessos de liberação sexual e de inversão dos papéis de gênero mais aceitos em nossa cultura.

C) INDIVIDUALIDADE - NORMALIDADE - AUTOVALORIZAÇÃO - HABILIDADE SOCIAL - Devido à diferença mar- 
cante entre os períodos quanto ao número de matérias e de menções aos valores, comparações quantitativas entre eles perdem sentido. Os Grupos de Valores mais citados nesta Categoria foram Autodeterminação, Benevolência e Segurança.

D) RELAÇÕES FAMILIARES - Categoria de Grandes Temas pouco abordada (6 matérias no $1^{\circ} \mathrm{P}$ e 3 no $2^{\circ} \mathrm{P}$ ). Os Grupos de Valores mais citados, nos dois Períodos, foram Tradição e Benevolência.

Em 1993/1995 verificamos ênfase maior nas conquistas que a adolescente pode realizar junto aos seus familiares (Grupo de Valor Realização), envolvendo mais liberdade, privacidade, autodireção e independência (Autodeterminação) e que se tornam mais fáceis de alcançar com uma boa dose de Conformidade, de aceitação de condições, e não de revoltas ou discussões.

O Grupo de Valores Tradição, nos dois Períodos, foi muito mencionado pelo fato da segurança familiar ser algo valorizado na maioria das matérias sobre a Categoria de Grandes Temas "Relações Familiares". No período 1999/2001 os Grupos de Valores mais enfatizados foram Tradição e Benevolência.

E) PROFISSÕES - Categoria com apenas uma matéria (bastante abrangente) no $1^{\circ} \mathrm{P}$. No $2^{\circ} \mathrm{P}$ apareceram seis matérias, a maioria tratando de profissões específicas, como modelo, atriz ou cantora. É interessante notar que são profissões compreendidas por muitos como "mágicas", pois dependeriam de habilidades pessoais que dispensam treinamento específico, além de estarem sujeitas a fatores casuais como "ser descoberta", visão que a revista contesta.

O Grupo de Valores Realização foi enfatizado nos dois Períodos. No $1^{\circ} \mathrm{P}$, relacionou-se mais ao êxito e a "obter o que se propõe”. Já no $2^{\circ} \mathrm{P}$, foi acrescentado ter ambição e obter sucesso, tendo em vista que riqueza e sucesso são aspectos que envolvem as profissões enfatizadas neste Período. Tais aspectos estão também relacionados ao Grupo de Valores Poder Social, enfatizado apenas neste Período.

No $1^{\circ} \mathrm{P}$ valorizou-se o aproveitamento, pela adolescente, de todas as oportunidades possíveis (Estimulação) visando alcançar seus objetivos, sem deixar de lado os momentos de lazer e descontração (Hedonismo). Manter a estabilidade pessoal, e ter vida organizada (Segurança), também foram pontos valorizados neste Período. Ter responsabilidade, cumprindo seus deveres e obrigações, também foi destacado (Conformidade).

F) DIFERENÇAS DE GÊNERO-COMPORTAMENTO MASCULINO (GERAL) Categoria abordada, como tema central, apenas no $1^{\circ} \mathrm{P}$. Os temas desvalorizados, na comparação entre os sexos, incluíram algumas características femininas como a menstruação e o sentimentalismo ou sensibilidade maior da mulher. Foram também desvalorizados: o machismo, o preconceito contra a mulher no trabalho, e a tese do homem ser intelectualmente superior à mulher.

\section{CONCLUSÕES POSSÍVEIS}

Um trabalho investigativo da natureza do que realizamos não permite falar em conclusões, pelo menos da forma como tal expressão é entendida em algumas outras modalidades de atividade científica. Ainda assim, é possível fazer considerações reunindo as constatações mais expressivas sobre as imagens da adolescência feminina na revista e sua relação com a formação de identidade, pessoal e de gênero, da adolescente.

Para efetuar estas relações, enfatizamos os temas abordados no modelo ideal (perfil) da adolescente identificado na revista Capricho por 
entendermos que se relacionam aos fatores cruciais que interferem no desenvolvimento das características pessoais que definem a individualidade, e na formação da identidade. São eles: a) Família; b) Amigos, Turma; c) Namorar, Ficar, Relacionar-se sexualmente; d) Escola, Profissionalização.

Foi possível constatar algumas mudanças na imagem/perfil da leitora de 1993/1995 para aquela de 1999/2001, apesar do pouco tempo decorrido.

No $1^{\circ} \mathrm{P}$ a grande ênfase na Categoria III (Individualidade - Normalidade - Autovalorização - Habilidade Social) indica um perfil de adolescente que costuma agir por influência dos outros, se sentindo pressionada, tendo dificuldade em estabelecer seus limites, em se afirmar como alguém única, com opiniões, desejos, preferências e necessidades próprias, o que equivale à dificuldade de constituir uma identidade bem definida. No $2^{\circ} \mathrm{P}$ parece comparecer uma leitora que recebe com mais naturalidade as transformações pelas quais passa, pois não deu um "salto radical" da infância para a adolescência, uma vez que já vem se informando e vivenciando aspectos da nova fase. Assim, sentimentos de inadequação ou de anormalidade deixam de ser tão freqüentes, pois, presume-se, não há um grande e brusco estranhamento de si mesma.

Acreditamos que isso se deva, em grande parte, ao maior acesso às informações e oportunidades possibilitadas não só àqueles que chamamos de pré-adolescentes, mas também às crianças, consumidoras de jogos inteligentes, video-games e computadores, sobretudo quando se fala de classe sócio-econômica com poder de consumo.

A própria televisão, meio de comunicação mais popularizado, veio trazer a diversos lares novas abordagens do mundo adolescente, proporcionando mais conversas e debates sobre assuntos pertinentes a esta fase (MIRA, 2001).

Talvez por isso a adolescente de Capricho do $1^{\circ} \mathrm{P}$, que ainda não fora coberta por essa avalanche de informações sobre a adolescência (e pré-adolescência), recebia da revista mais informações, para fazer com que compreendesse toda a série de mudanças que lhe percorrem a constituição física, o psiquismo e as relações com o ambiente social, e que estariam na origem de um possível - mas não inevitável estranhamento. Era visto como necessário que esta adolescente entendesse tais mudanças e aprendesse a importância de realizar suas próprias escolhas, tomar decisões, agir pelas próprias vontades, crenças e possibilidades (limitações em relação às pessoas e às condições materiais e culturais, entre outras). Ao mesmo tempo, foram enfatizados comportamentos de conformidade e tolerância em várias situações.

A existência de dois pólos de ação em que ora a adolescente deve se preocupar com sua autovalorização e com a realização de suas vontades, ora deve ser tolerante e conformarse com as limitações impostas, aproxima-se do que postula ANYON (1990) sobre desenvolvimento de gênero. A autora discorda da "visão prevalecente de que o desenvolvimento de gênero seja um processo unilateral de imposição, pela sociedade, de valores e atitudes internalizados pelas meninas" e entende que esse desenvolvimento "envolve tanto recepção passiva quanto resposta ativa às contradições sociais”, o que vai gerar "uma série de tentativas no sentido de se assemelharem a - e solucionarem - mensagens sociais contraditórias visando o que elas deveriam fazer ou ser” (p. 14).

Em relação à Família e às Relações Familiares, foi extremamente valorizada uma política da boa convivência, em ambos os períodos investigados. No $1^{\circ} \mathrm{P}$, valorizou-se principalmente a estratégia da adolescente negociar suas conquistas, buscar conversar com os pais (ensinando e aprendendo), promover debates sobre questões polêmicas (perguntando aos pais sobre eventos de sua juventude) e ter paciência com o aprendizado e as mudanças dos pais. Medidas autoritárias foram desvalorizadas, tanto as de iniciativa dos pais, como as da adoles- 
cente, quando tenta impor sua vontade a qualquer custo.

No $2^{\circ} \mathrm{P}$ as matérias sobre relações familiares pouco mudaram, mas abordaram a situação da adolescente diante de pais separados. De novo, enfatizou-se a boa convivência e, no caso da separação, não se culpar, não tomar partido nas brigas ou julgar o casamento dos pais. É importante separar a relação com os pais dos papéis desses como cônjuges.

Questões do âmbito de Amizades e Turmas foram abordadas em matérias que destacaram a importância de respeitar diferenças, e a importância de não transformar relações de amizade e de grupos em situações de dependência. $\mathrm{O}$ bom humor foi destacado como importante para a saúde do relacionamento com os pares.

A abordagem dos temas relacionados a namoro e sexo foi freqüente. Dúvidas sobre comportamento afetivo-sexual são (ainda) extremamente relevantes, considerando as expectativas das adolescentes femininas e a definição de papéis de gênero.

No $1^{\circ} \mathrm{P}$ destacou-se a possibilidade de "viver e ser feliz de várias maneiras", mesmo

sem namorado. Ainda assim, namorar foi muito

valorizado. É preciso não ter pressa ou ansiedade,

ser cautelosa na conquista, e não se precipitar em transar. Não se deve, ainda, iludir ou magoar as pessoas nas relações.

Observamos, nos dois Períodos, que o namoro foi privilegiado em relação ao "ficar". ANDRADE e NOVO (2000) afirmam que, da mesma forma que os jovens, alguns adultos (e pesquisadores) trazem consigo uma gama de valores que norteiam suas interpretações e análises sobre $\mathrm{o}$ adolescente. "Alguns tendem a avaliar, por exemplo, a ausência de compromisso do ficar com um esvaziamento do sentimento, aliando, desta forma, sentimento a permanência ou continuidade, herança do amor romântico instituído no século XIX” (p. 104). Esta associação entre sentimentos e relações duradouras não é "natural", ela foi construída historicamente e pode influenciar a valorização do namoro em detrimento do "ficar", já que buscar relações duradouras pode trazer, para a adolescente, benefícios valorizados socialmente.

No $1^{\circ} \mathrm{P}$ frisou-se que a adolescente não deve ser excessivamente desconfiada com 0 namorado, que ela deve "entender a cabeça masculina" e que, no "ficar", coloque limites e controle a ansiedade e o ciúme, não criando muitas expectativas.

Em tais prescrições, evidencia-se a ênfase na existência de um universo masculino e um universo feminino, cabendo à mulher entender não só o seu próprio universo de significados, crenças e comportamentos, mas também o do homem, o que sugere um aparente (e sutil) poder feminino implícito na possibilidade de entendimento dos dois universos. É possível estarmos diante de viés decorrente do fato de Capricho ser uma publicação feminina. Ainda assim, a solução editorial não precisaria ser sempre desse tipo.

No $2^{\circ} \mathrm{P}$ as menções a comportamentos de liberação sexual feminina ocorreram com freqüência aumentada, sendo destaques como temas desvalorizados. São exemplos: agir sem princípios ou não ter critérios de escolha para ficar com garotos, ter fama de "fácil”, além de transar por influência das amigas ou por pressão do menino.

Mesmo percebendo a conotação negativa de tais comportamentos, a revista não os aborda de forma moralista, confirmando estilo editorial que parece considerar que, se hoje a mulher adquiriu um certo nível de independência e de iniciativa nas áreas profissional, familiar, social e econômica, pode parecer incoerente para a adolescente que, no âmbito sexual e afetivo, ela ainda tenha que esperar pela escolha masculina.

Nos dois Períodos, relacionar-se sexualmente foi valorizado (mais no $2^{\circ} \mathrm{P}$ ), mas no momento certo, quando se sentir pronta, com consciência, naturalidade e intimidade, e com alguém que represente interesse genuíno. A pre- 
ocupação com gravidez e com AIDS (e outras DSTs) foi constante, com a camisinha sendo destacada como prevenção eficaz.

As matérias de Capricho apresentam abordagem bastante condizente com os oito pontos básicos para o conteúdo sexual responsável nos meios de comunicação, relacionados por STRASBURGER (1999). Tais pontos são: 1) Reconhecer o sexo como uma parte saudável e natural da vida; 2) Encorajar as discussões sobre sexo entre pais e filhos; 3) Discutir ou mostrar as conseqüências do sexo sem proteção; 4) Mostrar que nem todos os relacionamentos resultam em sexo; 5) Indicar que o uso de contraceptivos é essencial; 6) Evitar ligar a violência com o sexo; 7) Exibir o estupro como um crime de violência, não de paixão; 8) Reconhecer e respeitar a capacidade para dizer "não".

Os temas associados à questão da Profissionalização e da Escola apontaram a necessidade da adolescente aproveitar as oportunidades que têm, quase sempre relacionadas às condições sócio-econômicas das classes média e alta, porém, conciliando sempre os estudos com lazer e diversão.

No $1^{\circ} \mathrm{P}$ enfatizou-se a busca de objetivos e foi lançada uma edição especial sobre Profissões em setembro de 1995. A adolescente deve ser paciente e não pular etapas, o que pode indicar mais ansiedade percebida nas adolescentes neste Período. No $2^{\circ} \mathrm{P}$ as matérias abordaram profissões específicas, ligadas à fama, em paralelo à noção de cultura juvenil voltada ao prazer e ao entretenimento.

Os dados permitem esboçar uma síntese das características do "modelo ideal" de adolescente feminina que a revista apresenta e que, supostamente, não deve estar longe do que as próprias adolescentes gostariam de ser. Esse "modelo ideal" não seria idêntico nos dois períodos, mas também não seria fundamentalmente distinto. Tal modelo é compatível com a ênfase em determinados Grupos de Valores, como Benevolência, Autodeterminação e Segurança. É compatível, também, com as preocupações muito mais reduzidas com outros Grupos de Valores, tais como Poder Social, Estimulação e Tradição.

Um amplo panorama das características da adolescente modelo incluiria:

NO ÂMBITO DE SUA INDIVIDUALIDADE: 1) Agir pelas próprias opiniões, desejos, necessidades, mas considerando as possibilidades e as conveniências, ou seja, considerando limitações; 2) Ter o próprio espaço, conquistado através de boas relações, deixando claras suas discordâncias, mas sem se tornar rebelde, explosiva ou não adaptada; 3) Ser simpática, cordial e diplomática; 4) Cultivar o direito de ser diferente, mas aceitar as diferenças entre as pessoas; 5) Refletir sobre as crises para descobrir, aprender e crescer sem culpar os outros por elas; 6) Gostar de si mesma e se valorizar, para viver e ser feliz de várias maneiras; 7) Ser divertida, ter bom humor; 8) Ser independente e responsável.

NO ÂMBITO DE SUAS RELAÇÕES FAMILIARES: 9) Manter boas relações familiares apoiadas em diálogo, ensinando e aprendendo, negociando conquistas.

NO ÂMBITO DAS AMIZADES: 10) Cultivar amizades com base em afinidades reais, sem passar por cima de seus valores e de suas convicções.

NO ÂMBITO DO NAMORO E DO RELACIONAMENTO SEXUAL: 11) Agir com liberdade, pautando-se num equilíbrio entre ousadia e discrição; 12) Valorizar-se, fugir de toda vulgaridade, e ser conseqüente; 13) Saber controlar expectativas, ansiedades e ciúmes; 14) Evitar agir de forma a aumentar a chance de produzir mágoas, discussões e brigas; 15) Agir a partir de razões e reflexões próprias, e não por influência ou pressão de outros; 16) Relacionar-se sexualmente (inclusive na primeira vez) com consciência de estar com parceiro com quem tem afinidades, o que proporciona naturalidade e intimidade; 17) Conhecer e exercer cuidados de prevenção. 


\section{NO ÂMBITO DA ESCOLA PROFIS-} SIONALIZAÇÃO: 18) Não ficar esperando que as coisas aconteçam sem sua interferência e colaboração; 19) Conhecer vários aspectos da realidade para poder formular objetivos; 20) Aproveitar as oportunidades que se apresentem, sem a preocupação de queimar etapas e garantindo tempo para lazer e descontração.

STRASBURGER (1999) destacou que os adolescentes, em um período curto de tempo, precisam dominar um complexo conjunto de tarefas: 1) estabelecer um senso de identidade; 2) estabelecer sua independência em relação aos pais; 3) aprender a estabelecer relacionamentos com os próprios companheiros e com o sexo oposto; 4) terminar a escolarização formal; 5) começar a avaliar o próprio lugar na sociedade moderna e formular planos para uma carreira ou emprego. Exatamente dessas demandas é que fala uma publicação como a que analisamos.

É razoável pretender que as adolescentes que lêem as matérias de Capricho contam com um meio a mais para ampliarem seus conhecimentos, meio esse que supera as dificuldades de gerarem motivação suficiente para conseguir atrair e garantir a atenção que alguns outros meios enfrentam. Em outras palavras, a revista é buscada pela própria adolescente, sem necessidade de procedimentos que gerem motivação, como muitas vezes a escola precisa fazer (nem sempre com sucesso).
O processo investigado é de mútua influência. O material publicado pretende estar em sintonia com a realidade das adolescentes. A realidade das adolescentes sofre transformações relacionadas com diversos fatores (inclusive a partir do processamento das informações disponibilizadas pelos meios de comunicação). Tais transformações realimentam todo o processo de reflexão, de re-elaboração cultural, e de produção e difusão de novas informações.

Lembramos que foram analisadas matérias da seção em que a revista é menos limitada, não sendo possível avalizar como interessante tudo que a revista publica. Ainda assim, acreditamos que é possível dizer, pelo que constatamos nos dados, que a adolescência feminina é vivida, mais recentemente, com menos dificuldades e imposições, e com mais diversidade, criatividade e perspectivas do que já foi vivida não faz muito tempo. Estaria se desenhando um quadro com mulheres cada vez menos "talhadas" para a submissão. Seriam mulheres preparadas para lidar com o controle pleno de suas próprias vidas e para exercer a cidadania com todas as exigências que isso envolve. É um caminho ainda em construção, mas que parece apontar para um padrão mais saudável de relações de gênero e de redução de algumas modalidades de discriminações na vida social brasileira.

\begin{abstract}
Adolescents are privileged targets for cultural industry products. Much of the important information for their development is available in the mass media. In many countries, magazines containing information and recreational activities specific for teenage women consumption are published. This work identified, organized and analyzed concerns, behaviors and values portrayed in some thematic sections of the Capricho magazine in order to construct an overview of the images by means of which female adolescence is represented and idealized. One hundred and twenty-three (123) news pieces dealing with aspects of the adolescent relation to society were analyzed, comparing those published during the 1993-1995 period with those published during the 1999-2001 period. Data analysis revealed an "ideal model” of adolescent that manages to balance: a) autonomy and freedom and, on the other hand, respect to limits; b) values and views with dialogue; c) self-valorization with differences; d) various modes of pleasure and leisure with responsibility, prevention from vulgarity, violence and diseases; d) the full living of the demands of adolescence without negligence of planning and preparing for adult life.
\end{abstract}

Key-words: adolescence; female adolescence; mass media; values; identity. 


\section{REFERÊNCIAS BIBLIOGRÁFICAS}

ABRAMO, H.W. Cenas juvenis - punks e darks no espetáculo urbano. São Paulo: Scritta, 1994.

ANDI / IAS / UNESCO. Os Jovens na mídia: pesquisa. Brasília: ANDI - Agência de Notícias dos Direitos da Infância: Instituto Ayrton Senna: UNESCO, Coordenação: VIVARTA, V., 112 p. 1999. Disponível: http://www.andi.org.br

ANDRADE, A.N.; NOVO, H.A. "Eles ficam, nós namoramos": algumas reflexões sobre a adolescência. In: NOVO, H.A.; MENANDRO, M.C.S. Olhares diversos: estudando o desenvolvimento humano. Vitória: PPGP/UFES, 2000. p. 91-106.

ANYON, J. Interseções de gênero e classe: acomodação e resistência de mulheres e meninas às ideologias de papéis sexuais. Cadernos de Pesquisa 73:13-25, 1990.

BARDIN, L. Análise de conteúdo. Lisboa: Edições 70, 1977.

BASSANEZI, C.B. Virando as páginas, revendo as mulheres: revistas femininas e relações homemmulher, 1945-1964. Rio de Janeiro: Civilização Brasileira, 1996.

BUITONI, D.H.S. Mulher de papel: a representação da mulher pela imprensa feminina brasileira. São Paulo: Loyola, 1981.

BUITONI, D.H.S. Imprensa Feminina. São Paulo: Ática, 1986.

GROPPO, L.A. Juventude: ensaios sobre sociologia e história das juventudes modernas. Rio de Janeiro: Difel, 2000.

MARTINS, A.L. Revistas em revista: imprensa e práticas culturais em tempos de República, São Paulo (1890-1922). São Paulo: Edusp-Fapesp- Imprensa Oficial do Estado, 2001.
MINAYO, M.C.S.; ASSIS, S.G.; SOUZA, E.R.; NJAINE, K.; DESLANDES, S.F.; SILVA, C.M.F.P.; FRAGA, P.C.P.; GOMES, R.; ABRAMOVAY, M.; WAISELFISZ, J.J.; MONTEIRO, M.C.N. Fala, galera: juventude, violência e cidadania. Rio de Janeiro: Garamond, 1999.

MIRA, M.C. O leitor e a banca de revistas: $a$ segmentação da cultura no século $X X$. São Paulo: Olho d'Água / Fapesp, 2001.

MIRANDA-RIBEIRO, P.; MOORE, A. Já nas bancas: a saúde reprodutiva das adolescentes vista através das revistas Querida $e$ Capricho. Anais do XII Encontro Nacional de Estudos Populacionais - ABEP, 1997. Disponível: http://www.abep.org.br.

PARK, M.B. Histórias e leituras de almanaques no Brasil. São Paulo: Fapesp, 1999.

SODRÉ, M. O social irradiado: violência urbana, neogrotesco e mídia. São Paulo: Cortez, 1992.

STEINBERG, L.; MORRIS, A.S. Adolescent development. Annual Review of Psychology, 52: 83-110, 2001.

STRASBURGER, V.C. Os adolescentes e a mídia - impacto psicológico. Porto Alegre: Artmed, 1999.

TAMAYO, A.; SCHWARTZ, S.H. Estrutura motivacional dos valores humanos. Psicologia: Teoria e Pesquisa, 9(2): 329-348, 1993.

TAMAYO, A.L. Os valores do brasileiro: uma década de pesquisa. Cadernos de Psicologia, 1:113-134, 1997.

Recebido em 08/11/2002

Revisto em 16/12/2002

Aprovado em 20/12/2002 